УДК 330.341 .1

\title{
СМЕНА ТЕХНОЛОГИЧЕСКИХ УКЛАДОВ КАК СОЦИАЛЬНО-ЭКОНОМИЧЕСКИЙ ФЕНОМЕН
}

\author{
О.А. НАУМОВИЧ \\ канд. экон. наук, доцент, заведующий кафедрой \\ управления и экономики высшей школы \\ Республиканского института высшей школы, г. Минск
}

\begin{abstract}
Аннотация
В статье рассматриваются методологических подходы к изучению категории «технологический уклад», рассматривается влияние технологических укладов на сочиально-классовую структуру общества, изменение трудовых отношений, профессиональной структуры, материально-техническую базу, изменения в экономических отношениях. Определены движущие силь технологических укладов.

Ключевые слова: технологический уклад, производство, постиндустриальное общество, экономический рост, экономическое развитие, технологическое развитие.
\end{abstract}

\section{Abstract}

The article discusses the methodological approaches to the study of the category "technological structure», there is examined the impact of technological structures in the socialclass structure of society-round, changing labor relations, professional structure, material and technical basis, change in economic relations. Article determines the driving forces of techno-logical structures.

Key words: technological structure, production, post-industrial society, economic growth, economic development, technological development.

\section{ВВЕДЕНИЕ}

Современное состояние экономики характеризуется информационной революцией, пронизывающей производство, экономику, науку, сферу услуг. Все сферы приобретают новую систему взаимодействия. Свое развитие получают информационные услуги. Республика Беларусь обладает всеми предпосылками для инновационного развития - развитая система образования, высокая культура научных исследований. Поскольку страна обладает хорошим кадровым потенциалом, возникает необходимость его использования в развитии индустрии программного обеспечения или информационных технологий. Благодаря имеющимся специалистам, при условии создания необходимых экономических, организационно-институциональных и правовых условий, возможно создание совершенно новых технологий и на их основе - высокотехнологичной продукции. Научно-техническое развитие, производство высокотехнологичных, наукоемких продуктов является основой успешного экономического роста. В свою очередь, «высокие технологии служат стратегическим фундаментом политической и оборонной мощи страны, формирующим и определяющим ее статус в мире» [2].

Многоукладность как социально-экономический феномен может выступать как преимуществом, так и как недостатком экономики. Основным недостатком является относительная экономическая неэффективность использования эксполярными укладами хозяйственных ресурсов, что сдерживает развитие общества, управление социальноэкономическими процессами. С другой стороны, эксполярные уклады играют роль стабилизаторов, смягчают последствия социально-экономических трансформаций, на основе накопленных навыков зарождаются новые уклады. Доминирующие уклады во 
взаимодействии с эксполярными призваны обеспечить экономическую состоятельность государства. Для «ликвидации диспропорций, обусловленных технологической многоукладностью, и ускорения экономического роста необходим новый подход к системе экономического управления НТП, использующий положительный опыт индустриально развитых стран» [4, с. 408].

\section{РЕЗУЛЬТАТЫ И ИХ ОБСУЖДЕНИЕ}

На определенном этапе истории экономические уклады приобретают господствующее значение и функционируют как социально-экономическое целое. Доминирующие уклады развиваются, деградируют, сменяются новыми. Это формирует тенденции социально-экономического развития. Новый технологический уклад создает технические предпосылки для решения проблемы исчерпаемости ресурсов, обеспечивая прорыв в области освоения новых, ранее неизвестных ресурсов, а «всплеск и падение цен на энергоносители, мировой финансовый кризис - верные признаки завершающей фазы жизненного цикла доминирующего технологического уклада и начала структурной перестройки экономики на основе следующего уклада» [5, с. 17].

Развитие постиндустриального общества характеризуется изменением характера производства, упор в развитии экономики переносится из промышленности в сектор услуг. Любой технологический процесс состоит из ряда последовательно протекающих операций, взаимодействующих между собой и образующих определенные структуры, поэтому составным элементом модернизации технологических процессов является трансформация функционирующих в данной системе структур.

Однако, отсутствие стройных (внутренне непротиворечивых) понятийных рядов негативно сказывается в том плане, что любое, даже самое точное и совершенное определение (если оно не вписано адекватным образом в понятийный ряд, т.е. систему других взаимосвязанных понятий и категорий) не позволяет содержательно решить сложную многоуровневую задачу, не только раскрыть сущность того или иного технологического уклада как социально-экономического феномена, но и как определенной стадии развития человеческого общества, определенного этапа в развитии экономики, определенного этапа в развитии самого общества, жизни людей, политэкономически как феномена, но и одновременно раскрыть те факторы или сущность, почему оно возникло, т.е. его генезис. Необходимо показать, каким образом происходит изменение технологических укладов, под влиянием каких факторов. Это требует решения сложной комплексной многоуровневой задачи: не просто выбрать совершенные определения, являющиеся частным этапом познания реальной жизни, включая изменения новейшего технологического уклада, но и раскрыть его реальный механизм, что само по себе требует описания сопредельных категорий и предопределяет необходимость уточнения не одного, а нескольких понятий, которые могут быть после их конкретизации успешно вписаны в ряд других, уже разработанных учеными.

В работах данного направления наблюдается влияние технологических укладов на социально-классовую структуру общества, на изменение трудовых отношений, профессиональной структуры, в отношениях собственности, на материально-техническую базу производства, а также изменения в экономических отношениях. Отмечается, что становление нового высокотехнологичного уклада влечет за собой ряд изменений:

- модификация социального облика общественных групп;

- «существенная трансформация трудовых отношений и профессиональной структуры» [6, с. 485];

- внедрение новейших достижений научно-технической революции; становление «социально-научного сообщества» [6, с. 475];

- формирование нового «материально-общественного комплекса» [6, с. 465]; 
- «изменение технологической структуры экономики» [7, с. 55].

Последнее замечание само по себе не вызывает возражений. Названные теоретические взгляды отличаются от существующих историческим подходом к трактовке феномена высокотехнологичного уклада, рассмотрением его эволюции в неразрывной связи с динамикой экономических интересов, отказом от нормативного подхода (долженствования), а также уходом от этических (плохо/хорошо) оценок объективных экономических процессов.

В ряде случаев, исходя из абсолютизации институциональной методологии, где основу всех экономических действий предопределяют институты, смена технологических укладов характеризуется как «процесс конкуренции экономических институтов» [8, с. 27]. При институциональном подходе в большинстве случаев наблюдается абсолютизация роли институтов в экономической динамике и, соответственно, в раскрытии феноменологической социально-экономической природы технологического уклада. Вместе с тем, согласно теоретическому обоснованию рядом ученых взаимосвязи между социальным, человеческим, интеллектуальным капиталами и институтами (в работе «The New Comparative Economics»), каждое общество сталкивается с выбором между различными вариантами организации, определяемыми кривой институциональных возможностей. При таком подходе институты - это лишь точки на кривой, положение которой зависит от накопления иных форм капитала. Чем он (капитал) больше, тем привлекательнее и альтернативные институциональные возможности общества.

Исходя из приведенных методологических подходов к рассмотрению «технологичного уклада», под последним нами будет пониматься технологически сопряженный относительно обособленный, социально-экономический, персонифицированный и институционализированный способ хозяйства, сосуществующий с другим способом хозяйства.

Превращение научно-технологических преобразований в главный фактор экономического роста вызывает необходимость существенного повышения технологического уровня в приоритетных отраслях нового технологического уклада. Важной особенностью современных технологических преобразований является их комплексность, предполагающая охват всех основных сторон управления, всех уровней и звеньев национальной экономики.

Экономическое развитие характеризуется постоянной заменой производственных отношений на более совершенные. Прогресс в одних отношениях может сопровождаться регрессом в других. «Старый» уклад играет роль сырьевого придатка нового. Удержать свои конкурентные преимущества возможно путем постоянной разработки новых и передовых продуктов. Страны с развитыми экономиками могут повышать производительность путем внедрения уже существующих технологий.

Несмотря на имеющиеся знания и накопленный опыт перехода к новому технологическому укладу, не все страны могут успешно их применить. Среди основных факторов, препятствующих успешной смене технологических укладов, можно выделить следующие:

- многообразие подходов к высокотехнологичному укладу, отсутствуют выверенные понятийные ряды, когда понятия взаимосвязаны и не противоречат друг другу.

- отсутствие системности базовых категорий;

- отсутствие социально-экономического механизма смены технологических укладов;

- в каждой стране формируется свой уникальный, исторически обусловленный механизм перехода к новому технологическому укладу;

- отсутствие интеграционного аспекта, который позволил бы рассматривать технологический уклад как комплексный феномен.

В качестве фундамента для успешного долгосрочного развития экономики выделяется опережающее освоение ключевых производств ядра нового технологического 
уклада, дальнейшее расширение которых позволит получать интеллектуальную ренту в глобальном масштабе. Еще во время доминирования предыдущего технологического уклада происходит зарождение нового. Сегодня базовые инновации нового технологического уклада совершаются в результате качественного совершенствования ключевого фактора и ядра предшествующего технологического уклада, охватывающих микроэлектронную промышленность, программное обеспечение, энергетику, радиотехническую промышленность. В это время особенно актуальными становятся вопросы модернизации промышленности, организация, подготовка персонала. Как свидетельствует опыт, лишь немногие предприятия располагают необходимыми собственными средствами. В данный период решающую роль при принятии решений об инвестиционных проектах в нововведения играют управляющие банков, менеджеры венчурных фондов и другие финансовые агенты. Новаторы, которые первыми осваивают базовые нововведения, непосредственно создают предпосылки замещения прежнего технологического уклада новым, выступают в роли локомотива экономического развития, определяя его эффективность и рост производительности труда.

Движущими силами смены технологических укладов являются:

a) технический прогресс, который наряду с предприятиями приносит выгоду и государству, которая выражается в повышении конкурентоспособности отечественной продукции, увеличении налогов, которые поступают в казну; в присвоении мировой квазиренты («дифференцированный научно-технический доход, т.е. сверхприбыль, которую получают предприятия, первыми освоившие более эффективную, принципиально новую технику и получающие вследствие этого дополнительный доход») [11, с. 120]. В целом более высокий технический уровень национальной экономики выступает важнейшим фактором ее относительной независимости в условиях глобализации. Причиной смены укладов является технический прогресс. Вместе с тем, инновации, (являясь основой выхода из кризиса, его непременной частью) научно-технических циклов, «служат главным полем конкуренции, источником и стимулом экономического роста и социального прогресса» [11, с. 459], определяются как «путь в неведомое, это нарушение сложившегося образа жизни и действий, это большой риск» [11, с. 368];

б) конкуренция, которая «заставляет компании выбирать более совершенные способы развития, гарантирующие им выгодную позицию на рынке, ее удержание и/или расширение» [5, с. 336], «основным инструментом технологического отбора в рыночной экономике выступает конкуренция, механизм формирования инновационной сверхприбыли - инновационной квазиренты. Предприниматели, первыми освоившие эффективную инновацию, на какое-то время получают сверхприбыль - технологическую квазиренту. Тот, кто отстает в технологическом соревновании, терпит убытки и покидает поле экономической деятельности» [3, с. 394]. Обществу нужен «великий человек», способный создавать новые знания и разумно применять их в своей практической деятельности. В связи с этим, развитые страны мира во время кризиса резко увеличивают расходы на науку. Это делается потому, что без науки не будет никаких новых технологий и прорывов, «важнейшая функция фундаментальной науки в том и состоит, что она закладывает основы технологий будущего» [9, с. 22].

\section{ВЫВОДЫ}

Смена технологических укладов - это переходный социально-экономический период в экономике. Ни одной стране не удалось избежать кризисных процессов во время смены технологических укладов. Переход к новому технологическому укладу осуществляется синхронно, т.е. группами технических средств, материалов, «отсутствие такой синхронности, согласованности тормозит переворот в технике, ведет к появлению образцов, в которых принципиально новое техническое решение не может реали- 
зовать свой потенциал из-за отсутствия сопряженных средств, сочетается с элементами устаревших поколений техники» $[10$, с. 85]. Распределение богатства и достижений НТП происходит неравномерно. Основная доля научно-технических разработок сконцентрирована в развитых странах. Технологические инновации ослабляют зависимость от природных ресурсов, и увеличивают зависимость от разума. В постиндустриальной экономике ведущим фактором становятся знания, как когда-то в аграрной экономике этим фактором была земля. Доступ к мировым ресурсам научно-технической информации и возможности развития собственного потенциала обеспечиваются путем активного участия в международных, финансовых, торговых, производственных, научнотехнических, хозяйственных связях, а также включением в глобальную экономическую систему. Отсутствие высокотехнологичных корпораций выдвигает необходимость интеграции предприятий в мировую систему разделения труда. Технологическая интеграция оказывает влияние на структурную решетку экономики. Современные производственные мощности обладают способностью переключаться с производства одного вида продукции на другой, позволяя менять при этом производственные программы и рынки сбыта. Каждый новый продукт вытесняет старый.

\section{ЛИТЕРАТУРА}

1. Багриновский, К.А. Механизмы технологического развития экономики России = Mechanisms of technological development of Russia economy: макрои мезоэкономические аспекты / К.А. Багриновский, М.А. Бендиков, Е.Ю. Хрусталев ; Рос. акад. наук, Центр. экон.-мат. ин-т. - М. : Наука, 2003. - 375 с.

2. Бендиков, М.А. Высокотехнологичный сектор промышленности России = Russian high-technology industry: состояние, тенденции, механизмы инновационного развития / М.А. Бендиков, И.Э. Фролов ; Рос. акад. наук, Центр. экон.-мат. ин-т. - М. : Наука, 2007. - 582 с.

3. Конкурентоспособность России в глобальной экономике / А.А. Дынкин [и др.]. М. : Междунар. отношения, 2003. - 374 с.

4. Львов, Д.С. Экономика развития / Д.С. Львов. - М. : Экзамен, 2002. - 511 с.

5. Нанотехнологии как ключевой фактор нового технологического уклада в экономи-ке / С.Ю. Глазьев [и др.] ; под ред. С.Ю. Глазьева, В.В. Харитонова. - М. : Тровант, 2009. - 304 с.

6. Солодовников, С.Ю. Институциональные матрицы: сущность, персонификация и ее генезис : политико-экон. очерки / С.Ю. Солодовников. - Минск : Право и экономика, 2006. - 528 с.

7. Солодовников, С.Ю. Трансформация социально-классовой структуры белорусского общества: методология, теория, практика / С.Ю. Солодовников ; под науч. ред. П.Г. Никитенко. - Минск : Право и экономика, 2003. -272 с.

8. Фролов, Д. Теория кризисов после кризиса: технологии versus институты / Д. Фролов // Вопр. экономики. - 2011. - № 7. - С. 17-33.

9. Ханин, Г.И. Продолжение споров о судьбе российской науки / Г.И. Ханин. // ЭКО. - 2010. - № 5. - С. 11-19.

10. Яковец, Ю.В. Циклы. Кризисы. Прогнозы / Ю.В. Яковец. - М. : Наука, 1999. - $448 \mathrm{c}$.

11. Яковец, Ю.В. Эпохальные инновации XXI века / Ю.В. Яковец. - М. : Экономика, 2004. - 443 с.

Статья поступила в редакцию 17 ноября 2015 года. 